Article

\title{
Development of Wireless Power Transmission System for Transfer Cart with Shortened Track
}

\author{
Jae Sik Jin ${ }^{1}$, Sunghun Jung ${ }^{2} \mathbb{D}$ and Han Joo Kim ${ }^{3, *}$ \\ 1 Department of Mechanical Design, Chosun College of Science and Technology, Gwangju 61453, Korea; \\ jinjs@cst.ac.kr \\ 2 Department of Smart Mobile Convergence System, Chosun University, Gwangju 61452, Korea; \\ jungx148@chosun.ac.kr \\ 3 Department of Convergence Technology Engineering, Jeonbuk National University, Jeonju 54896, Korea \\ * Correspondence: khanjoo@jbnu.ac.kr; Tel.: +82-10-3863-1201
}

Received: 19 April 2020; Accepted: 7 July 2020; Published: 8 July 2020

\begin{abstract}
In this study, a wireless power transmission (WPT) system for high power was developed to supply the wirelessly powered transfer cart for a clean environment (such as liquid crystal display (LCD), semiconductor, and flat panel display (FPD) device industries) to improve the cleanliness of related industrial production lines and save energy. The power transmission method of WPT and the core design were optimized, and a shortened track was fabricated to enable WPT via short power lines for diverse applications in a small space-constrained workshop. In realizing the shortened Litz wire system, the amount of heat generated increased due to the increased resistance in the system, and efforts were made to improve the thermal performance. A simple approach was also proposed to estimate the skin depth caused by the skin effects in a cable made up of multiple strands of multiple wires, validated through thermal analysis by using ANSYS software in terms of heat generation by an electric field. Structure designs were implemented to improve the heat transfer performance, and the experimental results of WPT systems at a power level of $21.54 \mathrm{~kW}$ demonstrate that the power transfer distance of WPT was above $15 \mathrm{~mm}$ with a charging efficiency above $83.24 \%$.
\end{abstract}

Keywords: wireless power transmission; pickup module for the shortened track; wirelessly powered transfer cart; radio transmission distance; power transfer efficiency

\section{Introduction}

Wireless power transmission (WPT) is a technology that transmits electrical energy from source to load for a distance wirelessly. It is a continuous technological development, revolutionizing wireless charging and electric vehicle radios [1-12]. WPT can also be applied to various other applications, such as radio frequency (RF) identification, wireless buildings, codeless switches, batteryless sensors, and wirelessly powered drug release systems [2]. It converts electrical energy into an electromagnetic wave by converting electrical energy into an RF signal. This radio transmission technology is divided into two types: Short-distance transmission technology using magnetic fields and long-distance transmission technology using an antenna $[10,13]$. Most wireless power transmission technologies currently being developed are short-distance using magnetic fields [5,9].

In connection with this technology, different concepts have been proposed, which can be classified into two methods: The magnetic induction method (MIM) and the magnetic resonance method (MRM) [1,3,4,6,8,14-16]. The MIM transmits electric power using a magnetic field induced in a coil $[8,14]$. The concept of the MIM is that most of the magnetic field generated from the current flowing through the primary coil flows through the secondary coil, inducing current flows through the secondary coil to supply energy to the load. Such an energy transfer method is similar to the operation 
principle of a conventional transformer. The characteristic of the MIM is that the inherent resonance frequency of each coil differs from the transmission frequency that carries actual energy. This makes it possible to miniaturize the coil, but it also has the disadvantage that the distance, which can be transmitted, decreases as the size of the coil decreases. Presently, the MIM is applied for the wireless charging of portable devices and is also used for the wireless charging of some electric vehicles $[8,14]$. The MRM transfers energy using the resonance phenomenon between coils $[1,3,4,6,14-16]$. The MRM is similar to the MIM in that the magnetic fields generated from the current flowing through the primary coil pass through the secondary coil to induce the induction current, but the resonance frequency of the primary coil and the resonance frequency of the secondary coil are the same. The energy generated in the primary coil is transferred to the secondary coil through resonance mode energy coupling between the coils. The resonance frequency and the energy transmission frequency of each coil should be equal. Compared to the MIM, the MRM is advantageous in terms of the transmission distance as a result of the high-quality factor $(\mathrm{Q})$ of the resonator. However, in order to ensure high $\mathrm{Q}$, the size of each coil must be large compared to the MIM systems. Such a MRM can be applied to various fields, compared to the MIM [14-16].

All the main power equipment used today is powered through sockets and plugs. As a result, there are many problems to overcome to power all mobile devices. Power supplies such as a trolley bars are now available and devices such as carrier-like vehicles are generally a common way to supply power [17]. The transfer method using the sliding contact can cause serious problems in areas requiring a clean environment such as semiconductor factories due to wear and tear, as well as dirt, which contains metal, copper, and lead components.

To solve these problems, a non-contact power (NCP) supply has been developed, which is a method of transmitting electrical energy using magnetic induction phenomena without direct electrical or physical contact. This contactless power supply uses mechanical contactless magnetic coupling to transfer power to a load, eliminating the risk of electric shock in wet and dangerous environments, which enables safe power supplies in a clean environment. Especially, in recent years, the electric energy-based wirelessly powered transfer cart (we hereafter call it "transfer cart") has been applied to carry an object or a person for a precise manufacturing production in clean environments (including semiconductors or pharmaceuticals) and applications in a small space-constrained workshop [18]. In such a case, a magnetic levitation transfer cart is used to reduce the occurrence of dust. As the magnetic levitation feeder moves without direct contact with the rail without wheels, there is little frictional resistance, which results in very low noise and vibration, and high speed at low power. The power supply of such a transfer cart is generally used in a non-contact manner. That is, the transfer cart includes a power-receiving module provided with a pickup coil, and the power-receiving module is supplied with power in a magnetic induction manner through a high-frequency feed line installed along a moving section of the transfer cart. Therefore, WPT can be considered as an essential technology for various industrial applications $[2,5,9,19]$.

To be an efficient WPT system, improving the energy conversion efficiency and increasing the power transfer distance of WPT are essential $[3,5,6,8,9,11,13,15,16,18,20]$. In particular, for a variety of applications in the industry where a clean environment is required or when there is limited space in the workplace, it is necessary to be able to design a pickup module with a shortened track. Generally, the typical track length is long, and a trap box is installed in the middle of 100 to $200 \mathrm{~m}$ to meet the LC resonance. In this study, we designed and fabricated a pickup module for application to a shortened track with a length of 6 to $10 \mathrm{~m}$, and its performance was confirmed by performing experiments. In [21], they provide electromagnetic field analysis to improve the core performance and coil design for maximizing efficiency, and in [22], they propose some techniques for the reduction in electromagnetic fields (EMFs) from the power line and vehicle. In our design of the pickup unit including a regulator (secondary side) and a track (primary side) made of Litz wire (see Figure 1a,b), MRM-based design methods were originally developed for applications to wireless charging systems for electric vehicles of [21,22]. A previous conference paper has briefly introduced the potential of this strategy [23]. 
(a)

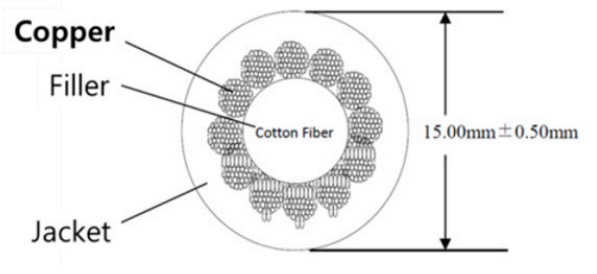

(b)

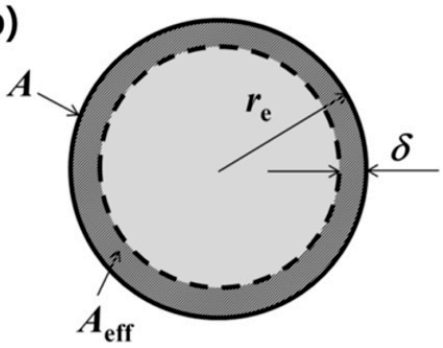

Figure 1. Schematics for modeling of Litz wire: (a) Distribution of actual wire and (b) effective area ( $\left.A_{\text {eff }}\right)$ of Litz wire due to skin effect. Here, $A$ is the overall area of the cable, $r_{\mathrm{e}}$ is the effective radius, and $\delta$ is the skin depth in the cable.

To improve the performance of the WPT system and to develop the module for a shortened track, the tasks we conducted in this work are:

1. Design to maximize efficiency considering several key design parameters of the coil,

2. Coil design considering high efficiency, electromagnetic interface (EMI), electromagnetic field (EMF), and form factor,

3. The selection of an appropriate frequency for maximum efficiency, minimum material loss, and minimum EMF,

4. An active shielding method using a resonant loop current shielding (RLCS) canceller,

5. Structural designs to improve the heat transfer performance of a module,

6. Module fabrication for performance verification.

To increase the efficiency of power transmission by increasing the reactance, the Litz cable is lengthened from 100 to $200 \mathrm{~m}$ in an industrial site. When the Litz cable is long, the line in the factory is complicated, resulting in limited space usage. Therefore, the Litz cable needs to be shortened. For this purpose, a module with a core structural shape was fabricated and applied in our study. This paper presents the power transfer system design in Section 2. Section 3 describes the thermal analysis and pickup module fabrication. Section 4 offers test methods and results. Lastly, Section 5 concludes the paper.

\section{Power Transfer System Design}

In general, coil design is considered the most important step in the physical implementation process of the WPT system to achieve high efficiency and maximum power transfer $[16,24,25]$. In the design of the coil, there are key design parameters of the coil including the resonance of the coil, ferromagnetic materials, and form factor $[5,9,16,20]$. We carefully designed a magnetic field according to the change in the coil position to take into account the ceiling type, sidewall type, and window type. This allows us to optimize the coil design for various supplied powers. The design of the magnetic field according to the change in the shape, size, and the first and second coil geometries of the used coil was performed. Coils are generally made using wound Litz wire in order to optimize energy efficiency [14]. As the energy transmission efficiency strongly depends on the coil materials, we studied the effects of various coil materials such as FPC (flexible printed circuit), PCB, metal, stranded wire, and Litz wire together with maximizing the field control and efficiency using the ferromagnetic substance. Details in the design of the coils and cores using the commercial simulation software ANSYS and SIMULINK are introduced in [21,22].

It is well known that the coil resistance generally increases as the frequency increases due to the skin effect [16]. Therefore, a coil design with a low amount of loss, which also helps to increase $\mathrm{Q}$, is important [16]. Thus, the coil design for improved WPT efficiency should be built upon to minimize the skin effects. The estimation of skin depth due to the effects will be discussed later. The power transfer efficiency is a function of the passive circuit parameters and operating frequency, 
and the power transfer efficiency is generally maximized at the resonance frequency [16]. To select an appropriate frequency, a correlation analysis was performed with respect to the variations in the frequency, coil size, coil shape, and the optimum frequency study with minimum EMF [9]. We studied the use of other devices in the selected frequency band and occupation relationship of the frequency spectrum. Then, we determined the efficiency of the active power conversion circuit according to the selected frequency. Through this process, we can select the optimum frequency according to the amount of power generation in our devices.

An active shielding technique was also employed by using the RLCS canceller by following the three steps below [16]. First, a study of the generation type of the anti B-field and form control technology according to the loop shapes was performed, and a beamforming study was then conducted using the loop array. This allowed us to draw an optimal layout. Second, using a controllable capacitor array, the loop impedance was controlled and the optimum impedance values were determined. Finally, we studied adaptive RLCS to dampen the EMF with feedback in real-time by measuring the EMF. This method is described at some length in [21,22].

The EMI minimization technology was also employed through the power circuit application and analysis of the spread spectrum technique [24]. By using the spread spectrum technique, the EMI can be reduced significantly [9].

In addition, to optimize the range of frequency control, we controlled the frequency of the transmission side. In addition, we used the spread spectrum implementation technique using the delay cell array and the programmable digital interface study. As a detailed discussion of the design processes described in this section is covered in [21,22], we just introduce the results of the implemented design in this study.

\section{Thermal Analysis and Pickup Module Fabrication}

\subsection{Thermal Analysis}

Litz wire is made up of multiple strands of multiple wires where a piece of string of copper has a diameter of $0.32 \mathrm{~mm}$, and there are 45 pcs in 12 strands (see Figure 1a).

As discussed in [26], serious power loss such as proximity effects can occur as turns of wiring increase in the system. Therefore, a single-turn cable is employed in this study, and as a result, we can neglect the power loss safely and propose a simple approach described below to estimate the skin depth caused by the skin effects in the cable. To estimate the heat generation owing to an electric field in a wire, the skin depth $[16,25]$ should be estimated. It is evident that the heat generation increases when the coil resistance increases, and therefore, the coil resistance has to be minimized by employing conductors of appropriate shapes and cross-sections. The conductor resistance is increased due to the skin effect, which distributes the current primarily on the surface of the conductor instead of uniformly over the cross-section [15]. As a piece of string of copper has a diameter of $d=0.32 \mathrm{~mm}$ and there are $540 \mathrm{pcs}$ (45 pcs $\times 12$ strands; see Figure 1a), the overall area of the cable $(A)$ is given by $A=\pi d^{2} / 4 \times 540$ pcs. Therefore, the effective radius $\left(r_{\mathrm{e}}\right)$ was obtained to be $r_{\mathrm{e}}=3.7181 \mathrm{~mm}$ from $A=\pi r_{\mathrm{e}}{ }^{2}$. The skin depth $(\delta)$ in the cable is caused by the skin effect. Here, $\delta$ depends on the frequency of the current, as well as the electrical and magnetic properties of the conductor, as follows [15],

$$
\delta=\sqrt{\frac{2}{\omega \sigma \mu}}
$$

where $\omega$ is the angular frequency of current ( $\omega=2 \pi f$ with frequency $f=20 \mathrm{kHz}), \sigma$ is the conductivity $\left(\sigma=5.8 \times 10^{7} \mathrm{~S} / \mathrm{m}\right.$ for $\left.\mathrm{Cu}\right)$, and $\mu$ is the permeability $\left(\mu=1.2566 \times 10^{-6} \mathrm{H} / \mathrm{m}\right.$ for $\left.\mathrm{Cu}\right)$. From the above relation, the skin depth was obtained as $\delta=0.4673 \mathrm{~mm}$. In order to verify the estimated skin depth, thermal analysis was conducted by establishing a model for the heat generation including the skin 
depth. The heat generation through a wire section made of copper in a duct is described in Figure $1 \mathrm{a}$. The heat generation per length $\left(q^{\prime}\right)$ can be expressed as follows [27],

$$
q^{\prime}=I^{2} \frac{R}{L}
$$

where $R / L$ can be written as $R / L=\rho / A_{\text {eff }}$ from the relationship of $R=\rho L / A_{\text {eff. }}$ Here, $I$ is the current (in this study, $I=125$ A with an RMS value of a $20 \mathrm{kHz}$ sine wave), $R$ is the resistance, $L$ is the duct length $(L=0.3 \mathrm{~m}), \rho$ is the copper resistivity $\left(\rho=1.68 \times 10^{-8} \Omega \cdot \mathrm{m}\right)$, and $A_{\text {eff }}$ is the effective area of the copper wire (refer to Figure $2 \mathrm{~b}$ ). To determine $A_{\text {eff }}$ of the copper cable, effective links between $\delta$ and $r_{\mathrm{e}}$ need to be established, as depicted in Figure $2 \mathrm{~b}$. $A_{\text {eff }}$ is easily calculated directly by $A_{\text {eff }}=\pi\left[r_{\mathrm{e}}{ }^{2}-\left(r_{\mathrm{e}}-\delta\right)^{2}\right]$. Using previously obtained $\delta$ and $r_{\mathrm{e}}$ and from Equation (2), the volumetric heat generation $\left(q^{\prime \prime}\right)$ is written as follows,

$$
q^{\prime \prime}=\frac{q^{\prime}}{A_{\text {duct }}}
$$

where $A_{\text {duct }}$ is the duct cross-sectional area (i.e., $A_{\text {duct }}=H \times W$; the rectangular cavity has internal dimensions of height $\mathrm{H}=18.8 \mathrm{~mm}$ and width $W=35.5 \mathrm{~mm}$, as represented in [23]). As a result, we obtained $q^{\prime \prime \prime}=38,674 \mathrm{~W} / \mathrm{m}^{3}$ for $I=125$ A.

(a)

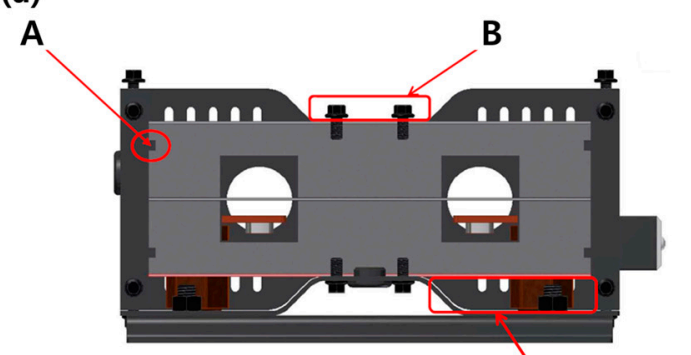

(b)

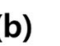

(c)

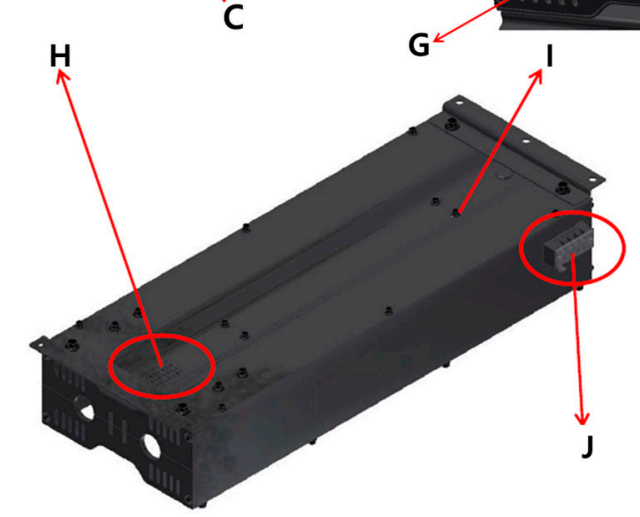

Figure 2. Pickup module prototype fabrication concept: (a) Front section view, (b) inside view of the rear part, and (c) three-dimensional view. The uppercase English alphabet represents design improvements to ensure mass production and reliability, and detailed descriptions of design improvements are described in the main text.

Simplified geometry of the WPT system was employed to minimize the calculation time of the system to the extent that the accuracy is not affected in the thermal analysis calculation. As mentioned previously, particular emphasis was placed on quantifying the skin depth caused by skin effects in the cable. The geometrical configuration used in the simulation is represented in [22] for the WPT system and the ducts for inserting cables. The basic thermal analysis considers a rectangular duct filled with a cable with a diameter of $15 \mathrm{~mm}$. Calculations were performed for all test cases using the commercial CFD (Computational fluid dynamics) package of ANSYS FLUENT 14.2. All simulations were performed using an Intel Core i7-5930K $3.5 \mathrm{GHz}$ processor, and a typical run required a computing 
time of about $1.5 \mathrm{~h}$. The momentum and heat fluxes were assumed to be laminar and the energy equation was solved under the condition of steady-state. At the surfaces of the duct, the heat flux was used as the thermal boundary condition. However, radiation heat transfer between the surfaces was neglected. No-slip boundary conditions were imposed for all solid surfaces. The Boussinesq approximation was used to specify the air density variation due to temperature [28]. The resulting relative variation in the air density was less than $2 \%$ inside the enclosure. We generated about a 2.66 million tetra grid and approximately 7.6 million nodes. For analytical accuracy, the grid size was created by using a sizing function with a growth rate of 1.2 and a non-uniform grid distribution from 0.35 to $70.83 \mathrm{~mm}$. The enclosure condition assumed that the WPT system was exposed to $20^{\circ} \mathrm{C}$ air, and convergence conditions were conducted until the remaining conditions for energy conservation were satisfied with the requirements of $10^{-6}$.

The simulation result shows that the maximum temperature, $T_{\max }$, is $46{ }^{\circ} \mathrm{C}$, which is about $4{ }^{\circ} \mathrm{C}$ lower (about $8 \%$ error) than that of the experimental data [23]. If we consider the existence of uncertainty in the system or the environment (for example, elusive effects such as interfacial thermal resistance, convective surface film coefficient, and complex geometries), it can be concluded that the temperature contours agree well with each other with a deviation of less than $10 \%$. In this study, all temperature measurements were performed using a thermographic camera (model: FLIR i5, max. $250{ }^{\circ} \mathrm{C}$, every $0.1{ }^{\circ} \mathrm{C}$ ). Although $T_{\max }$ is underestimated for the case of thermal analysis, our method to obtain values of $\delta$ and $r_{\mathrm{e}}$ is reasonable because the experimental conditions and the analytical conditions cannot be exactly the same, due to the computational limitations, as discussed above. Further investigation would yield additional insight into the skin effect dependence of the electric flow mechanism. For the convenience of thermal analysis, the effective property values are used because the exterior of the module is composed of a bakelite and ferrite core. The material properties of the exterior of the pickup module used in the analysis are listed in Table 1 . The effective values $\left(X_{\text {eff }}\right)$ are calculated by using the volume fraction of the bakelite $(\varphi)$ : $X_{\text {eff }}=\varphi X_{\text {Bakelite }}+(1-\varphi) X_{\text {Ferrite core. }}$ From the result, we also identified the physical properties of the external case of the module.

Table 1. Material properties of L-dummy used in the thermal analysis.

\begin{tabular}{cccc}
\hline Property & Bakelite & Ferrite Core & Effective Value \\
\hline Thermal conductivity $(\mathrm{W} / \mathrm{m} \cdot \mathrm{K})$ & 1.4 & 4.25 & 3.32 \\
Density $\left(\mathrm{kg} / \mathrm{m}^{3}\right)$ & 1300 & 5000 & 3794.9 \\
Specific heat $(\mathrm{J} / \mathrm{kg} \cdot \mathrm{K})$ & 1465 & 750 & 982.9 \\
Volume $\left(\mathrm{m}^{3}\right)$ & $1.58 \times 10^{-3}(32.6 \%)$ & $3.27 \times 10^{-3}(67.4 \%)$ & - \\
\hline
\end{tabular}

\subsection{Pickup Module Fabrication}

In this section, we discuss the fabrication of a pickup module that can be applied to a shortened track for a wide range of uses. The pickup module prototype production concept is shown in Figure 2.

In the figure, the " $\mathrm{A}$ " part is designed to fit into the groove to avoid up and down shake, and it is possible to assemble without additional tape processing, which reduces the assembly time. The bending design of the " $\mathrm{B}$ " part is implemented to remove the separate module intermediate fixing bracket by supporting the middle part and avoiding up and down shake. The bending design of the " $\mathrm{C}$ " part is employed to improve the cooling performance by allowing the fan wind to flow smoothly into the empty space and additionally minimize heat generation by the bolts. The " $\mathrm{D}$ " part is a round treatment to prevent tearing of the wire cloth by the module edge. The " $\mathrm{E}$ " part is the fitted design to support the module weight. The connection terminal block of the " $\mathrm{F}$ " part is installed so that the Litz wire connection terminates the assembly without additional fieldwork. The " $G$ " part is MC (machining center) machinery to minimize heat generation due to the lower natural cooling inlet and Litz wire. The " $\mathrm{H}$ " part represents the fan intake hole design, and the hole rectangle design is implemented to prevent shake due to the module tolerance at the " $\mathrm{I}$ " part. The "J" part is a symmetrical design of 
the side terminal block to make it easy to assemble to the left and right sides depending on the field conditions. The internal layout of the product is shown in Figure 3.

(a)
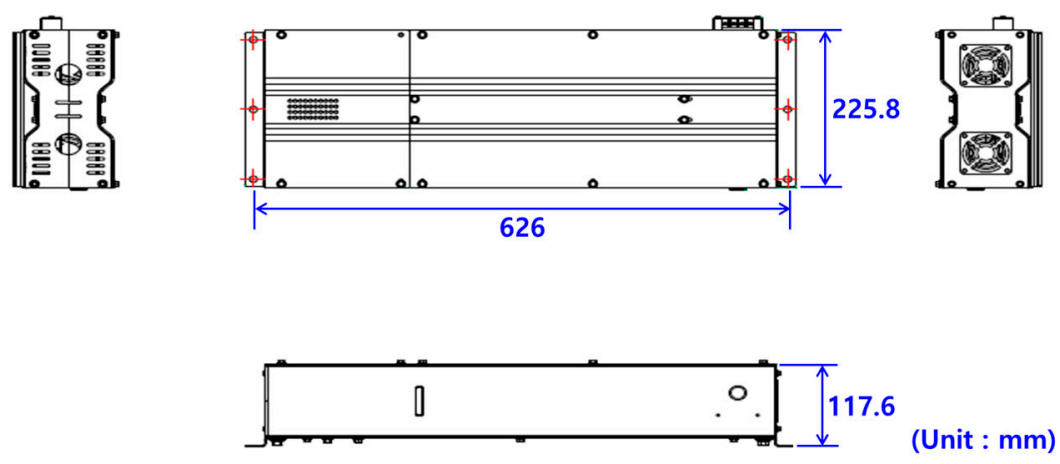

(b)

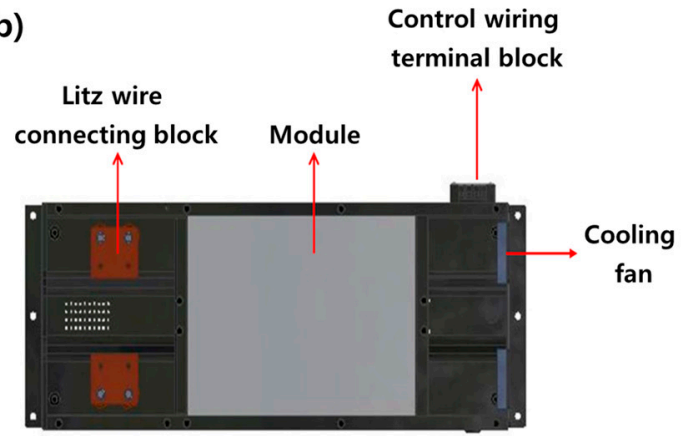

Figure 3. (a) The external dimensions of the manufactured prototype of the pickup module, (b) the internal layout of the pickup module. Several essential parts, such as the cooling fan, control wiring terminal block, and Litz wire connecting block, are installed inside of the product.

As shown in the figure, several essential parts, such as the cooling fan, control wiring terminal block, module, and Litz wire connecting block, are installed inside the product.

\section{Test Method and Result}

Using the manufactured module prototype, environmental experiments were carried out under the following conditions: Litz wire shortened track with a length of $8 \mathrm{~m}$, a continuous load of $5 \mathrm{~kW}$, a line current of $125 \mathrm{~A}$, a gap of $2.5 \mathrm{~mm}$ for the six core sets, and $\mathrm{L}=26 \mu \mathrm{H}$ for the module. The experimental system consists of a regulator, pickup module, and $20 \mathrm{kHz}$ converter. The fabricated module has to be covered by an exterior case to protect it from dust and contaminants in industrial sites. Before covering the exterior case, the inside temperature of the module itself was measured at $67^{\circ} \mathrm{C}$, and it was then covered by an exterior case made of steel. The inductance (L) for LC resonance was selected by constructing a dummy for a 6 to $10 \mathrm{~m}$ shortened track, but it was not applicable, due to its high temperature. We investigated the temperature increase in the module made of steel, keeping all other conditions the same. When we measured it by using the thermo-graphic camera, for the existing steel material, the temperature of the module increased to $100^{\circ} \mathrm{C}$.

As steel has a lower magnetic resistance compared to MC composites, the magnetic flux would pass through steel and "magnetization" would then occur in the steel, making it magnetic [29]. As a result, steel suffers from magnetic resistance, resulting in heat generation due to changes in the magnetic flux and magnetic resistance. On the other hand, the MC composite cannot pass magnetic flux, due to its almost infinite magnetic resistance, causing less heat generation. For the above reasons, the module was fabricated using the MC composite instead of the existing steel.

Now, we discuss structural design to enhance thermal performance under actual conditions of operation; we made three kinds of modules and called them "module A," "module B," and "module 


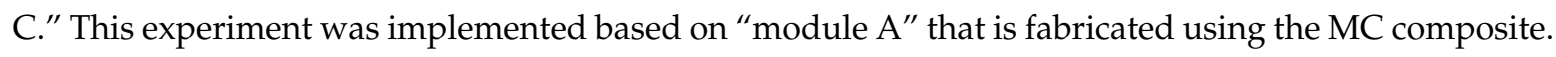
"Module B" was removed from the upper plate from "module A." "Module C" has the multi holes on the upper part of the "module B as shown in Figure 4.
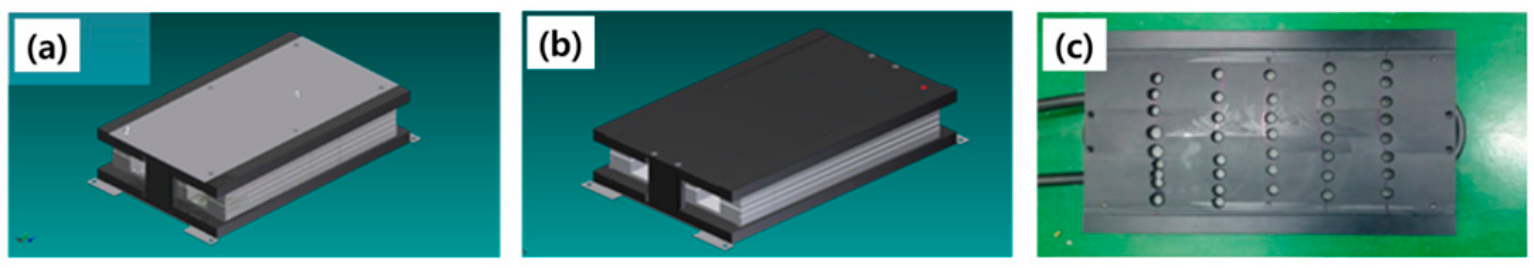

Figure 4. Three candidates of modified pickup modules to enhance thermal performance: (a) Module A, (b) module B, and (c) module C.

Experimental measurements of internal temperatures of "module $\mathrm{A}$ " were measured as $81{ }^{\circ} \mathrm{C}$, higher than the existing temperature of $67^{\circ} \mathrm{C}$ that was measured without an exterior case, as shown in Figure 5a. The inside temperature of the modified "module B" was measured lower by $10^{\circ} \mathrm{C}$ compared to "module A," as shown in Figure 5b, due to the removal of the upper plate. Lastly, the internal temperature of "module $C^{\prime \prime}$ was lowered by $2{ }^{\circ} \mathrm{C}$ rather than "module B," as shown in Figure $5 c$, due to the boring of multiple holes through the upper part.

(a)

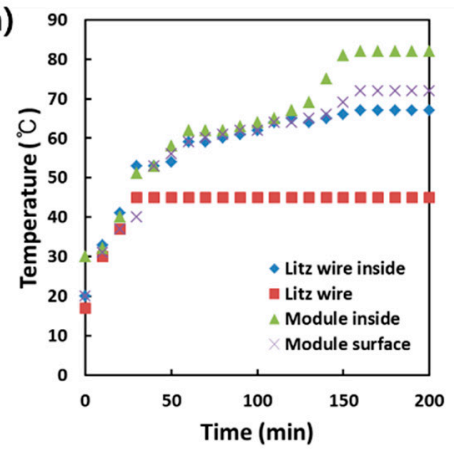

(b)

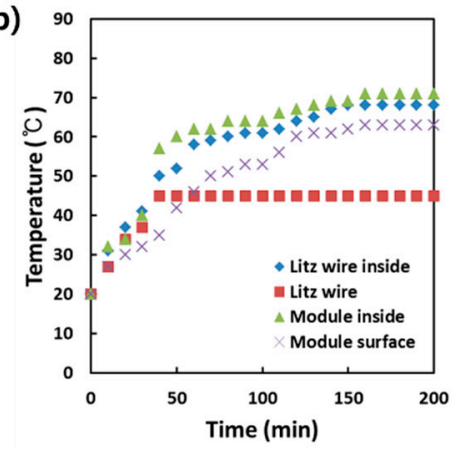

(c)

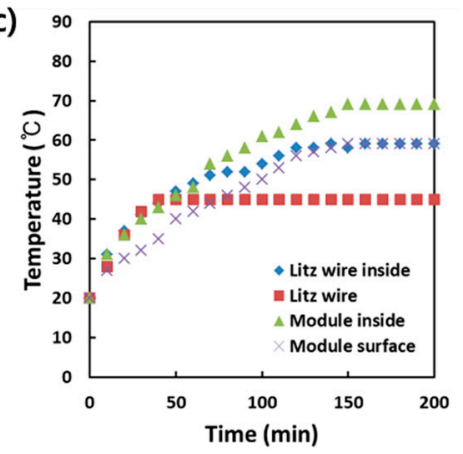

Figure 5. Experimental results of temperature measurement for three candidates: (a) Module A, (b) module B, and (c) module C.

An experiment for confirming the reliability of the performance of the manufactured module was conducted. The experimental configuration is briefly described here and the details can be found in [23]. Module C (Figure 4) was placed at the place labeled "pickup unit \& module" in Figure 6a. Then, regular three-phase AC $220 \mathrm{~V} / 440 \mathrm{~V} 60 \mathrm{~Hz}$ voltage was converted using an automatic transfer switch (ATS) to a single-phase $20 \mathrm{kHz}$ AC voltage, and a pickup unit was placed over a Litz cable, which flows the $20 \mathrm{kHz}$ AC voltage to examine the wireless charging efficiency. As the reactance value decreases due to the reduction in the length of Litz cable, the capacitance value must be adjusted to satisfy a given resonance frequency (here, $20 \mathrm{kHz}$ ). This is achieved through Bluetooth communication, as shown in Figure 6a. The wirelessly charged electricity from the pickup unit is now regulated to DC $300 \mathrm{~V}$ for other purposes. The maximum power capacity of the developed WPT system is $200 \mathrm{~kW}$. In our WPT system, AC to DC conversion is performed twice: On the primary coil and on the pickup sides, as shown in Figure 6. In our system, the voltages used for both the three-phase power source as an input and the coil for the transmission were 380 and $670 \mathrm{~V}$, respectively. If it was more than $200 \mathrm{~V}$, the efficiency would generally be $99 \%$ when considering the loss of the voltage drop caused by the diode used in the rectifier. Therefore, the effect of the performance of the rectifiers used in our system on the overall system would be negligibly small. In Figure 6b, we are looking at two places, labeled as 1 and 2, to check the wireless charging efficiency (see Table 2). 


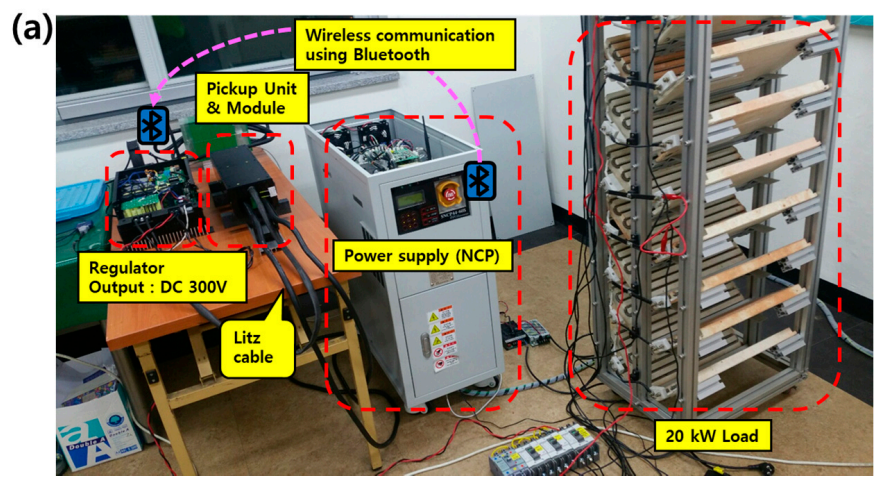

(b)

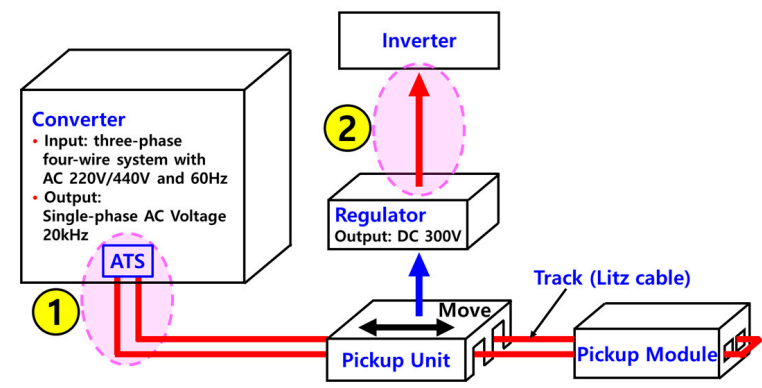

(c)

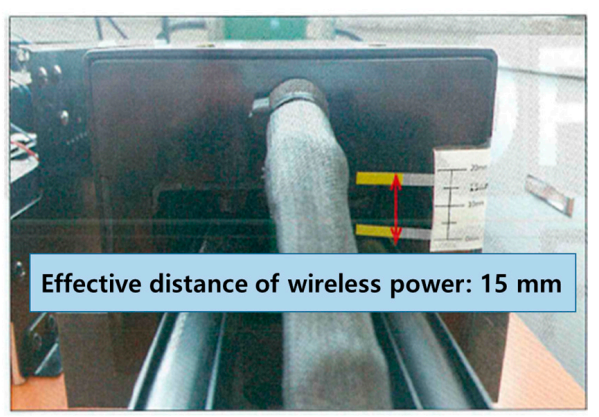

Figure 6. The actual experiment of power transfer capacity of L-module: (a) Instrument system setup (NCP: Non-contact power supply), (b) schematic diagram for overall setup of experiment (ATS: Automatic transfer switch), (c) effective distance of wireless power (15 mm) with charging efficiency of $83.24 \%$.

Table 2. Parameters related to power level between No.1 and No.2 shown in Figure 6a, and charging efficiency (83.24\%), which was measured based on $20 \mathrm{~kW}$.

\begin{tabular}{ccc}
\hline Parameter & No. 1 & No. 2 \\
\hline Voltage (V) & 318.06 & 287.80 \\
Current (A) & 81.34 & 74.83 \\
Power (W) & $25,871.0$ & $21,546.07$ \\
Charging efficiency (\%) & \multicolumn{2}{c}{83.24} \\
\hline
\end{tabular}

Specifically, its reference condition includes $\mathrm{L}=9 \mu \mathrm{H}$ for the module, and the coils are composed of single-turn Litz wire passing through it. The insulation resistance test and dielectric withstanding voltage test were passed. An aging experiment was conducted at $3 \mathrm{~kW}$ and the saturation temperature was kept below $50{ }^{\circ} \mathrm{C}$ except for the core part. We commissioned a performance evaluation experiment to the "Korea Electronics Technology Institute (KETI, Test Report: T2016-04-005, Tel: +82-63-219-0114, Fax: +82-63-219-0099)." We were able to obtain the results that the performance evaluation of the WPT system showed that at a $21.54 \mathrm{~kW}$ power level, the transfer distance of the WPT was above $15 \mathrm{~mm}$ with a charging efficiency above $83.24 \%$ (see Figure 6). 


\section{Conclusions}

We provided a design guide to maximize efficiency considering key design parameters such as the resonance coils, ferromagnetic bodies, and form factor. The coil was designed to maximize efficiency by minimizing the skin effect considering the high efficiency, EMI/EMF, and form factor. Our contributions can be summarized as follows.

1. An appropriate frequency was selected and active technology was developed by using an RLCS canceller.

2. Structural designs were achieved to improve high heat transfer.

3. A simple approach was also proposed to estimate the skin depth in a cable, which is made up of multiple strands of multiple wires. This approach was validated through thermal analysis by using ANSYS software considering heat generation by an electric field. The resulting temperature profile was in good agreement with those obtained from experiments.

4. We discussed the fabrication of a dummy for shortened tracks for diverse uses. To facilitate the application of the L-dummy, it was designed to fit in the shape of a hole and improve the cooling capacity of the dummy, thereby improving the cooling capacity of the system and minimizing the heat generated by the Litz wire to reduce the damage caused by the edges of the system.

In conclusion, the developed L-dummy shows that at a power level of $21.54 \mathrm{~kW}$ and $15 \mathrm{~mm}$ of power transfer distance, a charging efficiency above $83.24 \%$ can be achieved. This wirelessly powered transfer cart will improve cleanliness and save energy of related industrial production lines including liquid crystal display (LCD), semiconductor, and flat panel display (FPD) device industries.

Author Contributions: H.J.K. proposed the method in the paper and performed the experiments; J.S.J. and S.J. wrote the paper equally and contributed to the simulation; J.S.J. and S.J. analyzed the data and reviewed the paper. All authors have read and agreed to the published version of the manuscript.

Funding: This work was supported by the National Research Foundation of Korea (NRF) grant funded by the Korea government (MSIT) (No. 2020R1F1A1061754).

Acknowledgments: We express gratitude to Young-Joon Kim in the department of electronic engineering at Gachon University for his insightful assistance with the clarification of the rectifier performance of the WPT system.

Conflicts of Interest: The authors declare no conflict of interest.

\section{References}

1. Kurs, A.; Karalis, A.; Moffatt, R.; Joannopoulos, J.D.; Fisher, P.; Soljačic, M. Wireless Power Transfer via Strongly Coupled Magnetic Resonances. Science 2007, 317, 83-86. [CrossRef] [PubMed]

2. Tomar, A.; Gupta, S. Wireless power transmission: Applications and components. Int. J. Eng. 2012, 1, 1-8.

3. Wei, X.; Wang, Z.; Dai, H. A critical review of wireless power transfer via strongly coupled magnetic resonances. Energies 2014, 7, 4316-4341. [CrossRef]

4. Li, S.; Mi, C.C. Wireless power transfer for electric vehicle applications. IEEE J. Emerg. Sel. Top. Power Electron. 2015, 3, 4-17.

5. Das Barman, S.; Reza, A.W.; Kumar, N.; Karim, E.; Munir, A.B. Wireless powering by magnetic resonant coupling: Recent trends in wireless power transfer system and its applications. Renew. Sustain. Energy Rev. 2015, 51, 1525-1552. [CrossRef]

6. Song, M.; Iorsh, I.; Kapitanova, P.; Nenasheva, E.; Belov, P. Wireless power transfer based on magnetic quadrupole coupling in dielectric resonators. Appl. Phys. Lett. 2016, 108, 023902. [CrossRef]

7. Kim, Y.-J.; Ha, D.; Chappell, W.J.; Irazoqui, P.P. Selective wireless power transfer for smart power distribution in a miniature-sized multiple-receiver system. IEEE Trans. Ind. Electron. 2015, 63, 1853-1862. [CrossRef]

8. Rodríguez, E.S.G.; Ramrakhyani, A.K.; Schurig, D.; Lazzi, G. Compact low-frequency metamaterial design for wireless power transfer efficiency enhancement. IEEE Trans. Microw. Theory Tech. 2016, 64, 1644-1654. [CrossRef]

9. Bi, Z.; Kan, T.; Mi, C.; Zhang, Y.; Zhao, Z.; Keoleian, G.A. A review of wireless power transfer for electric vehicles: Prospects to enhance sustainable mobility. Appl. Energy 2016, 179, 413-425. [CrossRef] 
10. Nakamura, S.; Namiki, M.; Sugimoto, Y.; Hashimoto, H. Q Controllable Antenna as a Potential Means for Wide-Area Sensing and Communication in Wireless Charging via Coupled Magnetic Resonances. IEEE Trans. Power Electron. 2017, 32, 218-232. [CrossRef]

11. Lee, J.; Lee, K.; Cho, D.-H. Stability Improvement of Transmission Efficiency Based on a Relay Resonator in a Wireless Power Transfer System. IEEE Trans. Power Electron. 2017, 32, 3297-3300. [CrossRef]

12. Assawaworrarit, S.; Yu, X.; Fan, S. Robust wireless power transfer using a nonlinear parity-time-symmetric circuit. Nature 2017, 546, 387-390. [CrossRef] [PubMed]

13. Chen, M.; Gonzalez, S.; Vasilakos, A.; Cao, H.; Leung, V.C.M. Body area networks: A survey. Mob. Netw. Appl. 2011, 16, 171-193. [CrossRef]

14. Carretero, C. Coupling Power Losses in Inductive Power Transfer Systems With Litz-Wire Coils. IEEE Trans. Ind. Electron. 2017, 64, 4474-4482. [CrossRef]

15. Giovannetti, G.; Tiberi, G. Skin Effect Estimation in Radiofrequency Coils for Nuclear Magnetic Resonance Applications. Appl. Magn. Reson. 2016, 47, 601-612. [CrossRef]

16. Kim, J.; Kim, J.; Kong, S.; Kim, H.; Suh, I.-S.; Suh, N.P.; Cho, D.-H.; Kim, J.; Ahn, S. Coil design and shielding methods for a magnetic resonant wireless power transfer system. Proc. IEEE 2013, 101, 1332-1342. [CrossRef]

17. Jordan, E.; Balmain, K. Electromagnetic Waves and Radiating Systems; Prentice Hall: Upper Saddle River, NJ, USA, 1968.

18. Huang, M.-S.; Huang, Y.-L. Effect of multi-layered induction coils on efficiency and uniformity of surface heating. Int. J. Heat Mass Tranf. 2010, 53, 2414-2423. [CrossRef]

19. Jung, S.; Ariyur, K.B. Automated Wireless Recharging for Small UAVs. Int. J. Aeronaut. Space Sci. 2017, 18, 588-600. [CrossRef]

20. Zinn, S.; Semiatin, S. Coil design and fabrication: basic design and modifications. Heat Treat. 1988, 12, 32-36.

21. Suh, I.S. Application of shaped magnetic field in resonance (SMFIR) technology to future urban transportation. In Proceedings of the 21st CIRP Design Conference, Daejeon, Korea, 27-29 March 2011; pp. 226-232.

22. Ahn, S.; Pak, J.; Song, T.; Lee, H.; Byun, J.-G.; Kang, D.; Choi, C.-S.; Kim, E.; Ryu, J.; Kim, M.; et al. Low frequency electromagnetic field reduction techniques for the on-line electric vehicle (OLEV). In Proceedings of the 2010 IEEE International Symposium on Electromagnetic Compatibility, Fort Lauderdale, FL, USA, 25-30 July 2010.

23. Kim, H.J.; Song, J.H.; Jin, J.S. Design of WPT System using Optimized Dummy to Shorten Track. In Proceedings of the Korean Society of Mechanical Engineering 2018 Spring Annual Meeting of Honam Branch, Jeonju, Korea, 25 May 2018; KSME2018R1029. pp. 76-78.

24. Bash, B.A.; Goeckel, D.; Towsley, D. Limits of reliable communication with low probability of detection on AWGN channels. IEEE J. Sel. Areas Commun. 2013, 31, 1921-1930. [CrossRef]

25. Zhukov, A.; Talaat, A.; Ipatov, M.; Granovsky, A.; Zhukova, V. Estimation of the frequency and magnetic field dependence of the skin depth in Co-rich magnetic microwires from GMI experiments. J. Sci. Adv. Mater. Devices 2016, 1, 388-392. [CrossRef]

26. Hwang, K.; Chun, S.; Yoon, U.; Lee, M.; Ahn, S.; Chung, S. Thermal Analysis for Temperature Robust Wireless Power Transfer Systems. In Proceedings of the 2013 IEEE Wireless Power Transfer (WPT), Perugia, Italy, 15-16 May 2013; pp. 52-55.

27. Incropera, F.P.; DeWitt, D.P. Fundamental of Heat and Mass Transfer, 4th ed.; John Wiley \& Sons, Inc.: New York, NY, USA, 1996.

28. Versteeg, H.K.; Malalasekera, W. An Introduction to Computational Fluid Dynamics: The Finite Volume Method; Pearson Education: New York, NY, USA, 2007.

29. Joule, J. India-Rubber in: The Scientific Papers of James Prescott Joule; Taylor and Francis: London, UK, 1884; Volume 1.

(C) 2020 by the authors. Licensee MDPI, Basel, Switzerland. This article is an open access article distributed under the terms and conditions of the Creative Commons Attribution (CC BY) license (http://creativecommons.org/licenses/by/4.0/). 